\title{
Effect of cementation protocol on push-out bond strength of fiber posts to root canal
}

\author{
Denise S Casselli ${ }^{1}$, Marcela G Borges ${ }^{2}$, Murilo S Menezes ${ }^{2}$ and André L Faria-e-Silva ${ }^{3^{*}}$
}

\author{
* Correspondence: \\ fariaesilva.andre@gmail.com \\ ${ }^{3}$ School of Dentistry, Federal \\ University of Sergipe, Rua Cláudio \\ Batista s/n, Aracaju SE 49060-100, \\ Brazil \\ Full list of author information is \\ available at the end of the article
}

\begin{abstract}
The aim of this study was to evaluate the effect of adhesive protocol on the retention of glass-fiber posts luted into root canals. Thirty bovine incisors were endodontically treated and 9-mm-deep post holes were prepared. Fiber posts were luted using one of following protocols ( $n=10)$ : SB - Single Bond (3 M ESPE) with regular resin cement RelyX ARC (3 M ESPE); SBMP - Scotchbond Multipurpose Plus (3 M ESPE) associated with RelyX ARC; or UNI - the self-adhesive resin cement RelyX Unicem (3 M ESPE). After cementation, root/post specimens were transversally sectioned into 1-mm-thick slices, which were submitted to push-out testing in a mechanical testing machine. Bond strength data were analyzed by ANOVA $(a=0.05)$. There was no statistical difference between the adhesive protocols evaluated. Considering that the adhesive protocols evaluated showed similar bond strength values, simpler protocols must be preferable to lute fiber posts to root canal.
\end{abstract}

Keywords: Dental bonding; Post and core technique; Resin cements

\section{Background}

Several clinical trials have demonstrated a high success rate of glass-fiber post-retained restorations [1-3]. Failures like post de-bonding and fracture of post and/or core are the most common with the use of fiber posts [1-3]. The favorable failures and low incidence of root fracture are related mainly to similar elastic modulus properties between fiber posts and dentin [4]. Despite these advantages, proper luting procedures of fiber posts are essential to the longevity of the restoration. In addition to the loss of post retention, debonding of the fiber post to root canal dentin increases the risk of post/core fracture [5].

For many years, cementation of the fiber post to root canals was performed with resin cements associated with adhesive systems. However, bonding procedures to root canals is complex, impairing successful proper adhesion [6]. Possible incompatibility between the adhesive system and the resin cement can also occur and can additionally compromise the luting procedure [7].

Thus, manufacturers have developed simpler luting materials, such as self-adhesive cements. These cements do not require any pretreatment of dental substrate and are used in a single step [8]. Despite the facility of use, proper polymerization of the cement is essential to establish a stable bonding and increase its mechanical properties.

Usually, dual-cured resin cements are used to lute fiber posts. These materials were developed to provide proper working time and a high degree of conversion in the presence or absence of light. However, most of the dual-cured cements present a reduced degree of

(c) 2014 Casseli et al.; licensee Springer. This is an Open Access article distributed under the terms of the Creative Commons Attribution License (http://creativecommons.org/licenses/by/2.0), which permits unrestricted use, distribution, and reproduction in any medium, provided the original work is properly credited. 
conversion in the absence of light activation [9]. During the fiber post cementation into a root canal, only the exposed marginal areas of cement are directly irradiated by the light-curing unit. To compensate for this limitation of dual-cured resin cements, some manufacturers have developed primer and adhesive solutions containing coinitiators to enhance the polymerization of the cement [10-12]. Thus, the aim of this study was to evaluate the effect of adhesive protocols on push-out bond strength of fiber posts to root canals. The null hypothesis tested was that the adhesive protocol does not intervene on fiber post retention.

\section{Methods}

Thirty bovine incisors with mature apices and straight roots were selected for this study. The crowns were removed to standardize a 14-mm root height and the endodontic treatment was performed using a step-back preparation technique. All enlargement procedures were performed under irrigation with $2.5 \% \mathrm{NaOCl}$ solution. Prepared root canals were filled with gutta-percha cones and resin sealer (Sealer-26; Dentsply Caulk, Milford, USA) by the lateral condensation technique. Filled roots were stored in $100 \%$ relative humidity for 72 hours to set the resin sealer. Post holes measuring $9 \mathrm{~mm}$ in length were prepared using a \#4 Gates-Glidden drill (Dentsply/Maillefer, Ballaigues, Switzerland). Post surfaces were etched by immersion in $24 \% \mathrm{H}_{2} \mathrm{O}_{2}$ for 1 min [13] and silanized (RelyX Ceramic Primer; 3 M ESPE).

The fiber posts were luted with one of following procedures $(n=10)$ :

SB - The intraradicular dentin was etched with 37\% phosphoric acid for $15 \mathrm{~s}$ and rinsed; excess dentin moisture was removed using absorbent paper cones. A two-step, etch-and-rinse adhesive Single Bond 2 (3 M ESPE, St. Paul, MN, EUA) was applied, the solvent was evaporated for $20 \mathrm{~s}$, and photoactivation was performed for $20 \mathrm{~s}$ using a light-emitting diode unit (Radii Cal; SDI, Victoria, Australia) with $600-\mathrm{mW} / \mathrm{cm}^{2}$ irradiance. The dual-cured resin cement RelyX ARC was mixed and placed it over the posts, which was inserted into the root canals with light pressure. The excess of luting material was removed and light activation was performed for $40 \mathrm{~s}$.

SBMP - The intraradicular dentin was etched, rinsed and the excess of water removed similarly to SB group. The Scotchbond Multipurpose Plus (3 M ESPE, St. Paul, MN, EUA) activator was applied into the root canal with a microbrush of compatible size and air-dried for $5 \mathrm{~s}$. Afterwards, the primer, followed by Catalyst, were applied and air-dried. The resin cement RelyX ARC was inserted and light-cured for $40 \mathrm{~s}$, after the excess removal.

UNI - The root canal walls were rinsed with water using a syringe and then gently dried with paper points. The self-adhesive cement RelyX Unicem (3 M ESPE, St. Paul, MN, USA) was mixed and placed over the posts, which was inserted into the root canal with light pressure. The excess of luting material was removed and light activation was performed for $40 \mathrm{~s}$.

The compositions of all materials used for adhesive cementation are described in Table 1. After fiber post cementation, the samples were stored in distilled water at $37^{\circ} \mathrm{C}$ for 1 week. Next, each root was sectioned into 6 slabs with $1 \mathrm{~mm}$ of thickness. Slabs were observed under an optical microscope (DFC 280, Leica microsystems, Wetzlar, Germany) at $40 \times$ magnification. Dimensions (radius and perimeter) of the top and 
Table 1 Composition of the materials used for adhesive cementations

\begin{tabular}{|c|c|}
\hline Material & Main components* \\
\hline \multirow[t]{2}{*}{$\begin{array}{l}\text { RelyX ARC } \\
\text { (regular resin cement) }\end{array}$} & $\begin{array}{l}\text { Base paste: Bisphenol-A glycidyl dimethacrylate, Triethyleneglycol } \\
\text { dimethacrylate, dimethacrylate polymer, camphorquinone, amine. }\end{array}$ \\
\hline & $\begin{array}{l}\text { Catalyst paste: Bisphenol-A glycidyl dimethacrylate, Triethyleneglycol } \\
\text { dimethacrylate, dimethacrylate polymer, benzoylperoxide. }\end{array}$ \\
\hline \multirow[t]{2}{*}{$\begin{array}{l}\text { RelyX unicem } \\
\text { (self-adhesive resin cement) }\end{array}$} & $\begin{array}{l}\text { Base paste: Methacrylate monomers containing acid groups, methacrylate } \\
\text { monomers, silanated fillers, initiator components, stabilizer. }\end{array}$ \\
\hline & $\begin{array}{l}\text { Catalyst paste: Methacrylate monomer, alkaline fillers, silanated fillers, } \\
\text { initiator components. }\end{array}$ \\
\hline $\begin{array}{l}\text { Single bond } 2 \\
\text { (2-step etch-and-rinse adhesive) }\end{array}$ & $\begin{array}{l}\text { Bisphenol-A glycidyl dimethacrylate, 2-hydroxyethyl methacrylate, } \\
\text { diurethane dimethacrylate, polyalkenoic acid copolymer, camphorquinone, } \\
\text { dihydroxyethyl p-toluidine, water, ethanol, silica. }\end{array}$ \\
\hline \multirow[t]{3}{*}{$\begin{array}{l}\text { Scotchbond multi-purpose plus } \\
\text { (2-step etch-and-rinse adhesive) }\end{array}$} & $\begin{array}{l}\text { Primer: 2-hydroxyethyl methacrylate, Coploymer of acrylic and itaconic } \\
\text { acids, water. }\end{array}$ \\
\hline & $\begin{array}{l}\text { Catalyst: Bisphenol-A glycidyl dimethacrylate, 2-hydroxyethyl methacrylate, } \\
\text { Benzoyl peroxide, Triphenylphosphine, Triphenylantimony, Hydroquinone. }\end{array}$ \\
\hline & Activator: Ethyl Alcohol, Sodium Benzenesulfinate. \\
\hline
\end{tabular}

*As provided by the manufacturers.

bottom surfaces of the post were recorded to calculate the lateral area of the post in each slab. The slabs were positioned on a push-out jig in a mechanical testing machine (model 4411; Instron, Canton, USA). A compressive load was applied at a crosshead speed of $0.5 \mathrm{~mm} / \mathrm{min}$ until the post was dislodged. The push-out bond strength values (MPa) were calculated by dividing the maximum load by the lateral area of the GFP. Bond strength values of all slabs from the same root were averaged. The data showed normality and equal variance. Thus, data were submitted to ANOVA $(\alpha=0.05)$. Statistical analysis was performed using SigmaStat statistical software version 3.5 (Systat Software, Point Richmond, USA).

\section{Results and discussion}

ANOVA did not show a significant effect for adhesive procedure $(P=0.116)$. The results of bond strength are displayed in Figure 1. There was no significant difference between any adhesive protocols evaluated, while the null hypothesis tested was accepted. Other studies evaluating cementation of fiber posts have also found similarity of bond strength between self-adhesive cements and multiple-step protocols [14-16].

The fundamental principle of bonding to the tooth substrate is based upon a micromechanical interlocking by which the inorganic phase of dentine is exchanged for adhesive resin [17]. The resin adhesive diffuses through the collagen fibril exposed by etching and forms a so-called "hybrid layer" with them [17]. However, the steps to obtain proper bonding interface are difficult in a root canal [6], due to the complexity of the adhesive procedure because of both the difficulty of humidity control and adhesive light-activation. The adhesive protocol SB used an etch-and-rinse adhesive, while the moist control and adhesive light-curing are critical steps. The use of absorbent paper cones seems be an effective approach to moisture control in root canals [6,7]. Furthermore, adhesive light-activation for $20 \mathrm{~s}$ (twice the manufacturer's recommendation) is able to improve the bond strength to the dentin of the root canal [18]. 


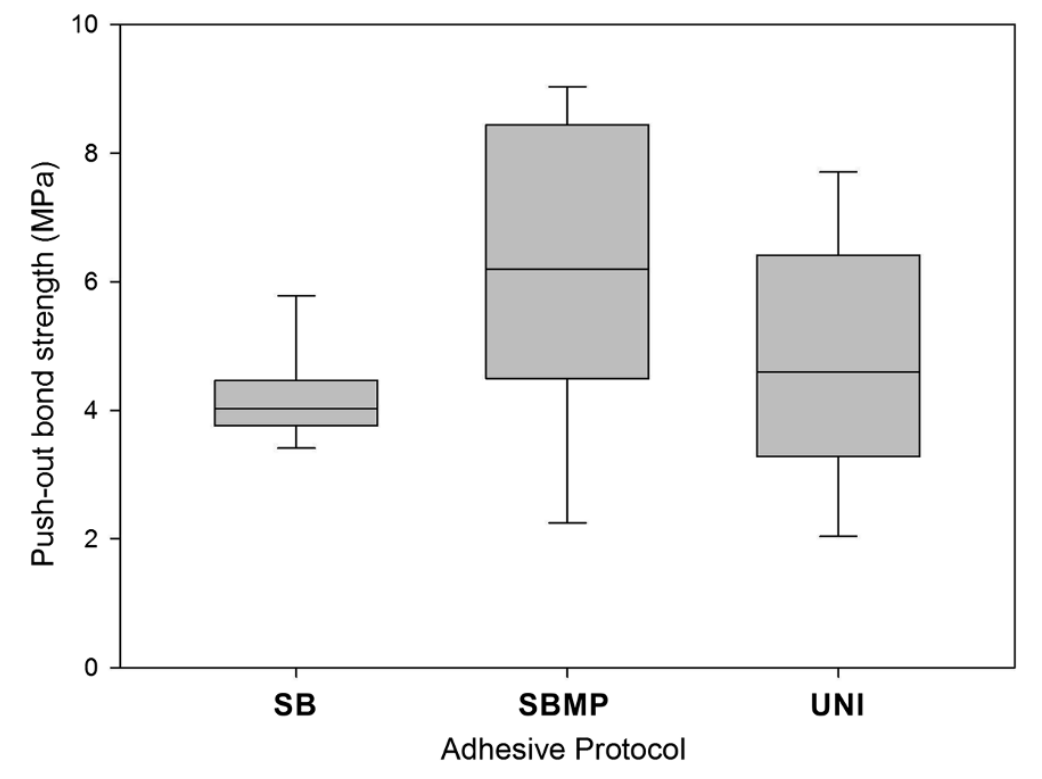

Figure 1 Results for push-out bond strength.

Unlike with SB, the adhesive protocol used in SBMP does not require the use of adhesive resin, eliminating the step of adhesive light activation. The process uses only a primer containing hydrophilic monomers and solvents to permit the interaction of hydrophobic resin cement with the demineralized dentin. Furthermore, the use of activator and catalyst are able to improve the resin cement polymerization [12]. The activator contains a sulfinic acid salt that reacts with the polyalkenoic acid co-polymer of the primer to generate free radicals, while the catalyst containing benzoyl peroxide increases the self-cure mechanism in dual-cured cement $[10,11]$. The possible improvement in the degree of conversion might have allowed a higher bond strength with SBMP than SB [12]. However, the high viscosity of the resin cement does not permit the formation of an effective hybrid layer, compensating a probable higher degree of conversion [19].

The self-adhesive resin cement used in this study showed similar values of bond strength to other adhesive protocols. Manufacturers have marketed self-adhesive resin cements to simplify the clinical procedures and overcome the technique sensitivity of multiple-step systems. According to manufacturers, these resin-based materials do not require any pretreatment of the dental surfaces and their main adhesive mechanism is attributed to a chemical reaction between phosphate methacrylates and hydroxyapatite [8,20-22]. However, the formation of a thick and dense smear layer during the root canal instrumentation [23] impairs a proper contact between the acidic methacrylates of self-adhesive cements and the underlying dentin, compromising the bond strength $[24,25]$.

Considering the outcomes of this study, which showed the absence of difference between the adhesive protocols, the use of single-step adhesive protocols (self-adhesive resin cements) seem clinically preferable due their procedure times. A recent systematic review of in vitro studies showed that SARC use could improve the retention of GFPs into root canals [26]. Furthermore, self-adhesive cements have demonstrated clinical outcomes similar to conventional multi-step cementation procedures $[27,28]$. 


\section{Conclusions}

Within the limitations of this in vitro study, the use of a single-step self-adhesive resin cement RelyX Unicem resulted in similar values of bond strength to multiple-step adhesive protocols using RelyX ARC, associated with Single bond 2 or Scotchbond Multi-purpose Plus. Thus, as the simplest application protocol, the use of a singlestep self-adhesive resin cement seems clinically preferable.

\section{Competing interests}

The authors declare they have no competing interests.

\section{Authors' contributions}

DSMC and MSM participated in the study design, data collection, data interpretation, manuscript drafting and critical revision. MBF participated in the laboratory analyses, data collection and critical revision. ALFS participated in the study design, data interpretation, manuscript drafting, and critical revision. All authors read and approved the final manuscript.

\section{Author details}

${ }^{1}$ School of Dentistry, Campus of Sobral, Federal University of Ceará, Rua Coronel Estanislau Frota s/n, Sobral CE 62010-560, Brazil. ²School of Dentistry, Federal University of Uberlândia, Av. Pará 1720, Bloco 4L, Uberlândia MG 38400-902, Brazil. '3 School of Dentistry, Federal University of Sergipe, Rua Cláudio Batista s/n, Aracaju SE 49060-100, Brazil.

Received: 19 November 2013 Accepted: 9 December 2013

Published: 2 September 2014

\section{References}

1. Nauman M, Koelpi M, Beuer F, Meyer-Luckel H (2012) 10-year survival evaluation for glass-fiber supported postendodontic restoration: a prospective observation clinical study. J Endod 38:432-435

2. Schmitter M, Hamadi K, Rammelsberg P (2011) Survival of two post systems - five-year results of a randomized clinical trial. Quintessence Int 42:843-850

3. Ferrari M, Vichi A, Fadda GM, Cagidiaco MC, Tay FR, Breschi L, Polimeni A, Goracci C (2012) A randomized controlled trial of endodontically treated and restored premolars. J Dent Res 91:725-78S

4. Balkaya MC, Birdal IS (2013) Effect of resin-based materials on fracture resistance of endodontically treated thin-walled teeth. J Prosthet Dent 109:296-3030

5. Santos AF, Meira JB, Tanaka CB, Xavier TA, Ballester RY, Lima RG, Pfeifer CS, Versluis A (2010) Can fiber posts increase root stresses and reduce fracture? J Dent Res 89:587-91

6. Amaral M, Rippe MP, Bergoli CD, Monaco C, Valandro LF (2011) Multi-step adhesive cementation versus one-step adhesive cementation: Push-out bond strength between fiber post and root dentin before and after mechanical cycling. Gen Dent 59:e185-e191

7. Faria e Silva AL, Casselli DS, Ambrosano GM, Martins LR (2007) Effect of the adhesive application mode and fiber post translucency on the push-out bond strength to dentin. J Endod 33:1078-1081

8. Ferracane JL, Stansbury JW, Burke FJ (2011) Self-adhesive resin cements - chemistry, properties and clinical considerations. J Oral Rehabil 38:295-314

9. Faria-e-Silva AL, Piva E, Lima GS, Boaro LC, Braga RR, Martins LR (2012) Effect of immediate and delayed light activation on the mechanical properties and degree of conversion in dual-cured resin cements. J Oral Sci 54:261-266

10. Faria-e-Silva AL, Moraes RR, Ogliari FA, Piva E, Martins LR (2009) Panavia F: the role of primer. J Oral Sci 51:255-259

11. Arrais CA, Giannini M, Rueggeberg FA (2009) Effect of sodium sulfinate salts on the polymerization characteristics of dual-cured resin cement systems exposed to attenuated light-activation. J Dent 37:219-227

12. Faria-e-Silva AL, Mendonça AA, Garcez RM, Oliveira AS, Moreira AG, Moraes RR (2012) Adhesion strategy and early bond strengths of glass-fiber posts luted into root canals. Braz Oral Res 26:485-487

13. Menezes MS, Queiroz EC, Soares PV, Faria-e-Silva AL, Soares CJ, Martins LR (2011) Fiber post etching with hydrogen peroxide: effect of concentration and application time. J Endod 37:398-402

14. Macedo VC, Faria eSilva AL, Martins LR (2010) Effect of cement type, relining procedure, and length of cementation on pull-out bond strength of fiber posts. J Endod 36:1543-1546

15. Gomes GM, Gomes OM, Reis A, Gomes JC, Loguercio AD, Calixto AL (2013) Effect of operator experience on the outcome of fiber post cementation with different resin cements. Operat Dent 38:555-564

16. Macedo VC, Souza NA, Faria e Silva AL, Cotes C, da Silva C, Martinelli M, Kimpara ET (2013) Pullout bond strength of fiber posts luted to different depths and submitted to artificial aging. Operat Dent 38:E1-E6

17. Marshall SJ, Bayne SC, Baier R, Tomsia AP, Marshall GW (2010) A review of adhesion science. Dent Mater 26:11-16

18. Aksornmuang J, Nakajima M, Foxton RM, Tagami J (2006) Effect of prolonged photo-irradiation time of three self-etch systems on the bonding to root canal dentine. J Dent 34:389-397

19. De Munck J, Vargas M, Van Landuyt K, Hikita K, Lambrechts P, Van Meerbeek B (2004) Bonding of an auto-adhesive luting material to enamel and dentin. Dent Mater 20:963-971

20. Gerth HUB, Dammaschke T, Zuchner H, Schafer E (2006) Chemical analysis and bonding reaction of RelyX Unicem and Bifix composites - a comparative study. Dent Mater 22:934-941

21. Al-Assaf K, Chakmakchi M, Palaghias G, Karanika-Kouma A, Eliades G (2007) Interfacial characteristics of adhesive luting resins and composites with dentine. Dent Mater 23:829-839

22. Monticelli F, Osorio R, Mazzitelli C, Ferrari M, Toledano M (2008) Limited decalcification/diffusion of self-adhesive cements into dentin. J Dent Res 87:974-979 
23. Violich DR, Chandler NP (2010) The smear layer in endodontics - a review. Int Endod J 43:2-15

24. Pavan S, Santos PH, Berger S, Bedran-Russo BK (2010) The effect of dentin pretreatment on the microtensile bond strength of self-adhesive resin cements. J Prosthet Dent 104:258-264

25. Pisani-Proença J, Erhardt MC, Amaral R, Valandro LF, Bottino MA, Del Castillo-Salmerón R (2011) Influence of different surface conditioning protocols on microtensile bond strength of self-adhesive resin cements to dentin. J Prosthet Dent 105:227-235

26. Sarkis-Onofre R, Skupien JA, Cenci MS, Moraes RR, Pereira-Cenci T (2013) The role of resin cement on bond strength of glass-fiber posts (GFPs) luted into root canals: A systematic review and meta-analysis of in vitro studies. Operat Dent, doi:10.2341/13-070-LIT

27. Taschner M, Kramer N, Lohbauer U, Pelka M, Breschi L, Petschelt A, Frankenberger R (2012) Leucite-reinforced glass ceramic inlays luted with self-adhesive resin cement: a 2-year in vivo study. Dent Mater 28:535-540

28. Peumans M, Voet M, De Munck J, Van Landuyt K, Van Ende A, Van Meerbeek B (2013) Four-year clinical evaluation of a self-adhesive luting agent for ceramic inlays. Clin Oral Investig 17:739-750

doi:10.1186/2196-4351-2-15

Cite this article as: Casselli et al:: Effect of cementation protocol on push-out bond strength of fiber posts to root canal. Applied Adhesion Science 2014 2:15.

Submit your manuscript to a SpringerOpen ${ }^{\circ}$ journal and benefit from:

- Convenient online submission

- Rigorous peer review

- Immediate publication on acceptance

- Open access: articles freely available online

- High visibility within the field

- Retaining the copyright to your article 